\title{
STAN BADAŃ NAD HISTORIĄ RODZINY STOLBERG-WERNIGERODE Z DÖNHOFFSTÄDT ORAZ DOTYCZĄCE JEJ ARCHIWALIA W ZASOBIE Archiwum Państwowego w Olsztynie
}

Słowa kluczowe: Dönhoffowie, Dönhoffstädt, Drogosze, zasób Archiwum Państwowego w Olsztynie, Stolberg-Wernigerode

Ke y w ord s : Dönhoffowie, Dönhoffstädt, Drogosze, State Archives in Olsztyn, Stolberg-Wernigerode

Abstract

Artykuł zawiera przegląd dziewiętnasto- i dwudziestowiecznych niemieckich publikacji heraldycznych i genealogicznych, biogramów poszczególnych członków rodu Stolberg-Wernigerode z Dönhoffstädt oraz charakterystykę zawartości materiałów archiwalnych z zespołu archiwum rodziny Dönhoff, przechowywanych w Archiwum Państwowym w Olsztynie.

Dönhoffstädt (Drogosze, pow. kętrzyński) to nazwa posiadłości, którą wschodniopruski ród Dönhoffów założył na początku XVIII wieku w pobliżu należącej do nich wsi Gross Wolfsdorf (Wilkowo Wielkie, pow. kętrzyń- 
ski). Utworzona w latach 1710-1714 rezydencja stała się główną siedzibą, a także centrum administracyjnym wielkiego klucza majątków jednej z pruskich linii tego rodu, zwanej Dönhoffstädt. Dobra ziemskie, zgromadzone przez Dönhoffów, pozostały w ich posiadaniu do lat siedemdziesiątych XIX wieku. Wtedy to przeszły w drodze koligacji małżeńskich na śląską linię rodu Stolberg-Wernigerode, która zarządzała nimi do 1945 roku.

Stolbergowie-Wernigerode to stary ród hrabiowski ${ }^{1}$, nieznany zupełnie w polskiej historiografii. Jego pochodzenie, a także rozwój poszczególnych linii odtworzyć można głównie dzięki XIX i XX-wiecznym niemieckim publikacjom heraldycznym i genealogicznym, a także biogramom poszczególnych członków rodu. Nie dają one jednak pełnego obrazu życia i działalności tej rodziny. Milczeniem pominięta została zwłaszcza śląska linia Stolberg-Wernigerode, która odziedziczyła majątek pruskiej linii rodu Dönhoff z Dönhoffstädt. Jej losy zapisane zostały w aktach Archiwum rodziny Dönhoff, przechowywanych w Archiwum Państwowym w Olsztynie. Mimo to historia rodziny Stolbergów-Wernigerode nie doczekała się opracowania i do dziś pozostaje w cieniu Dönhoffów.

Podstawowe źródło wiedzy o dziejach rodu stanowi publikacja autorstwa znanego pruskiego archiwisty i genealoga, Georga Adalberta von Mülverstedt. To wydawnictwo źródłowe, opublikowane w 1883 roku, przedstawiające pochodzenie rodu Stolberg, a także jego losy do początków wieku XVI².

Równie ważną pozycję stanowi Almanach Gotajski, rocznik genealogiczny wydawany w językach niemieckim i francuskim w latach 1763-1944, a od 1956 roku ukazujący się pod nazwą Genealogisches Handbuch des Adels. To wielotomowa publikacja, opisująca genealogię rodów, których szlachectwo zostało dawniej uznane bądź nadane przez panujących w państwach języka niemieckiego ${ }^{3}$. Wśród wy różnionych w niej rodzin znaleźli się także Stolberg-Wernigerode, których pochodzenie, a także rozwój poszczególnych linii opis. 56.

${ }^{1}$ E. H. Kneschke, Neues allgemeines deutsches Adels-Lexikon, Bd. 9, Leipzig 1861,

2 Geschichte des Hauses Stolberg vom Jahre 1210 bis zum Jahre 1511. Aus dem Nachlasse des verewigten Autors, hrsg. von G. A. von Mülverstedt, Kgl. Preuß. Staatsarchivar und Geheimen Archivrat, Magdeburg 1883.

${ }^{3}$ Geschichte des Gothaischen Hofkalenders (Almanach de Gotha), 1764-1863, [w:] A. Petermann, Mittheilungen aus Justus Perthes geographischer Anstalt über wichtige neue Erforschungen auf dem Gesammtgebiete der Geographie, Gotha. Justus Perthes, 1862, s. $475-478$. 
sany został zarówno w Gothaischer Genealogischer Hof-Kalender', jak i Genealogisches Handbuch des Adels.

Cennym źródłem wiedzy o historii rodziny Stolberg-Wernigerode pozostają także publikowane przez niemieckich heraldyków leksykony genealogiczne. Do najbardziej znanych i powszechnie dostępnych należą pochodzące z XIX wieku Neues Preußisches Adelslexikon 6 , a także Neues allgemeines deutsches Adels-Lexikon ${ }^{7}$. To publikacje stanowiące kompendium wiedzy na temat genezy i rozwoju pruskich rodów szlacheckich.

Według informacji w nich zawartych, Stolberg-Wernigerode to ród wywodzący się z Turyngii, którego najstarszym, potwierdzonym źródłowo przedstawicielem był Heinrich Graf v. Stolberg. Pierwsze wzmianki na jego temat pochodzą z dokumentów z lat 1213, 1216, 1222, 1225, 1231. Najstarszą siedzibą rodu było Stolberg 8 .

Jak podają L. von Zedlitß-Neukirch i Ernst Heinrich Kneschke, rozwój fortuny Stolbergów nastąpił w pierwszej połowie XV wieku. W tym czasie w ich posiadaniu znalazło się też Wernigerode w Saksonii, późniejsza główna siedziba jednej z linii rodu. Do pierwszego, trwałego podziału majątku Stolbergów doszło w 1645 roku. Wówczas wyodrębniły się dwie linie - starsza, zwana Stolberg-Wernigerode, i młodsza, Stolberg-Stolberg?.

Niestety, zarówno Neues Preussisches Adelslexicon, jak i Neues Allgemeines deutsches Adels-Lexicon nie podają szczegółowych danych na temat poszczególnych członków tych linii rodu. Braki te częściowo uzupełnia Allgemeine Deutsche Biographie ${ }^{10}$ - wielotomowe kompendium biograficzne, wydawane przez komisję historyczną Bawarskiej Akademii Nauk w latach 1875-1912, a także stanowiący jego kontynuację słownik Neue Deutsche Biographie ${ }^{11}$, ukazujący się od 1953 po dzień dzisiejszy. Biogramy w nich zawarte dostar-

${ }^{4}$ Gothaischer Genealogischer Hof-Kalender, Gotha. Justus Perthes, 1774-1942.

5 Genealogisches Handbuch der Fürstlichen Häuser, Limburg a. d. Lahn: SA Starke Verlag 1956.

${ }^{6}$ L. von Zedlitß-Neukirch, Neues Preussisches Adels-Lexicon oder genealogische und diplomatische Nachrichten von den in der preussischen Monarchie ansässigen oder zu derselben im Bezichung stehenden fürstlichen, gräflichen, freiherrlichen und adeligen Häusern, Bd. 4, Leipzig 1842, s. 239-242.

7 E. H. Kneschke, dz. cyt., s. 56-59.

8 Tamże, s. 56; L. Zedlitß-Neukirch, dz. cyt., s. 239-240.

9 Tamże.

10 Allgemeine Deutsche Biographie, t. 1-56, Leizig: Duncker \& Humblot, 1875-1912.

11 Neue Deutsche Biographie, Berlin : Duncker \& Humblot, 1953. 
czają głównie informacji dotyczących pochodzenia, wykształcenia, działalności wojskowej, politycznej opisywanych osób. W Allgemeine Deutsche Biographie opisanych zostało ponad trzydziestu przedstawicieli rodu Stolberg, pochodzących zarówno z linii Stolberg-Wernigerode, jak i Stolberg-Stolberg.

Śląskie losy rodziny Stolberg-Wernigerode zostały zarówno w leksykonach, jak i słownikach biograficznych w zasadzie pominięte. Natrafić w nich można jedynie na wzmianki dotyczące śląskich posiadłości, które Promnitzowie podarowali Stolbergom-Wernigerode w roku $1765^{12}$. Brak jest natomiast jakichkolwiek informacji na temat przedstawicieli śląskiej linii rodu. Lukę tę po części wypełnia wydany w 1857 roku Alphabetischer Nachweis (Adresbuch) des in den Preussischen Staaten mit Rittergütern angesessenen Adels ${ }^{13}$. Jak sama nazwa wskazuje, to alfabetyczny spis dóbr rycerskich w państwie pruskim, zawierający prawie dziesięć tysięcy nazwisk szlachty, z czego ponad dziewięćset nazwisk szlachty śląskiej bądź posiadającej na terenie Śląska swe posiadłości w połowie XIX wieku. Cennym źródłem informacji na ten temat jest także wydany w 1810 roku Ueber die Gräfliche Würde in Shlesien ${ }^{14}$, przestawiający rodowód szlachty śląskiej.

Bogatych informacji dostarczają ponadto herbarze szlachty śląskiej. Herb Stolbergów-Wernigerode opisany został w wydanym w 1847 roku Schlesisches Wappenbuch oder die Wappen des Adels im Souverainen Herzogthum Schlesien, der Grafschaft Glatz und der Oberlausizt ${ }^{15}$, a także w Wappen=und Handbuch des in Schlesien (einschlieslich der oberlausitz) landgesessenen Adels ${ }^{16}$, wydanym w latach 1901-1904. Współczesne źródło wiedzy na temat herbów szlachty śląskiej stanowi natomiast Herbarz szlachty śląkiej: informator genealogiczno-heraldyczny ${ }^{17}$, napisany przez Romana Sękowskiego.

Badając historię rodu Stolberg-Wernigerode, warto zajrzeć też do malowniczego albumu, poświęconego rezydencjom szlacheckim z terenu Królestwa Prus w XIX wieku, autorstwa Alexandra Dunckera. Die ländlichen Wohnsitze,

12 E. H. Kneschke, dz. cyt., s. 56-59; L. Zedlitß-Neukirch, dz. cyt., s. 239-240.

13 K. Fr. Rauer, Alphabetischer Nachweis (Adresbuch) des in den Preussischen Staaten mit Rittergütern angesessenen Adels, Berlin 1857.

14 G. S. Bandtke, Ueber die Gräfliche Würde in Schlesien, Berslau 1810.

15 Leonard Dorst, Schlesisches Wappenbuch oder die Wappen des Adels im Souverainen Herzogthum Schlesien, der Grafschaft Glatz und der Oberlausizt, Goerlitz 1847.

16 Wappen=und Handbuch des in Schlesien (einschlieslich der oberlausitz) landgesessenen Adels, Alfred Freiherrn von Krane, Goerlitz 1901-1904.

17 R. Sękowski, Herbarz szlachty ślaskiej: informator genealogiczno-heraldyczny, Katowice 2002-2008. 
Schloesser und Residenzen der ritterschaftlichen Grundbesitzer in der preussischen Monarchie ${ }^{18}$ to szesnastotomowa publikacja zawierająca dziewięćset sześćdziesiąt rycin posiadłości szlacheckich wraz z opisami, a także informacjami ta temat ich właścicieli. Wśród nich znalazły się między innymi Stolberg, Wernigerode, śląskie Kreppelhoff, Jannowitz, a także odziedziczona przez Stolbergów-Wernigerode posiadłość Dönhoffstädt w Prusach Wschodnich.

Wreszcie wspomnieć należy o wydanej w 2010 roku pozycji Stolberg 1210-2010. Zur achthundertjährigen Geschichte des Geschlechts ${ }^{19}$. To publikacja opisująca głównych przedstawicieli tego rodu. Wśród nich znalazł się między innymi Heinrich I, Botho II zu Stolberg, Christoph Friedrich zu Stolberg-Stolberg, Christian Ernst Graf zu Stolberg-Wernigerode, a także Christian Friedrich zu Stolberg-Wernigerode, z którego osobą wiążą się początki śląskiej linii Stolberg-Wenigerode. Opisana została też najstarsza siedziba rodu Stolberg.

Historia Stolbergów-Wernigerode z Dönhoffstädt to wątek z reguły pomijany w niemieckich publikacjach. Linia ta do dziś pozostaje w cieniu Dönhoffów i w zasadzie nie ma w tym nic dziwnego. Dönhoffowie należeli obok Dohnów, Finckensteinów, Lehndorfów, Eulenburgów czy Schwerinów do najbardziej wpływowych rodzin w Prusach Wschodnich. Piastowali wysokie godności w administracji i wojsku pruskim. Zgromadzili na terenie Prus rozległą fortunę, która drogą dziedziczenia przez kobiety przeszła w drugiej połowie XIX wieku na śląską linię hrabiów Stolberg-Wernigerode. Stąd też wzmianek na temat Stolbergów-Wernigerode szukać należy głównie w opracowaniach poświęconych Dönhoffom bądź ich siedzibie, zwanej Dönhoffstädt. Przykładem tego jest wydana w latach sześćdziesiątych XX wieku książka Ernesta Hartmanna, przedstawiająca dzieje posiadłości Gross Wolfsdorf i Dönhoffstädt ${ }^{20}$. Opracowanie to przedstawia Stolbergów-Wernigerode jako ostatnich właścicieli Dönhoffstädt.

Ubogi stan badań nad historią rodziny uzupełniają archiwalia, pochodzące z Archiwum Dönhoffów, przechowywanego w Archiwum Państwowym

18 A. Duncker, Ländlichen Wohnsitze, Schlösser und Residenzen der Ritterschaftlichen Grundbesitzer in der Preussischen Monarchie, Berlin 1857-1883.

19 Stolberg 1210-2010. Zur achthundertjährigen Geschichte des Geschlecht, hrsg. von P. Fürst zu Stolberg-Wernigerode und J.-C. Fürst zu Stolberg-Stolberg, Dößel 2010.

20 E. Hartmann, Gross Wolfsdorf und Dönhoffstädt. Ostpreußische Herrensitze im Kreise Rastenburg. Wissenschaftliche Beiträge zur Geschichte und Landdeskunde Ost-Mitteleuropas herausgegeben vom Johann Gottfried Herder-Institut, nr 74, Marburg 1966. 
w Olsztynie. Archiwum Dönhoffów to zespół liczący czterysta pięćdziesiąt trzy jednostki archiwalne, obejmujący chronologicznie okres 1685-1945. Jego granice terytorialne wyznaczają dobra ziemskie, należące do Dönhoffów linii Dönhoffstädt. Archiwum to, podobnie jak inne archiwa rodowe terenu Prus Wschodnich, składa się z trzech typów archiwaliów: osobistych i rodzinnych (Familienarchiv), administracyjno-gospodarczych (Gutsarchiv), władztwa zwierzchniego. Spośród zachowanych materiałów archiwalnych blisko sto dotyczy Stolbergów-Wernigerode. Nie odzwierciedlają one całości dziejów rodu, stanowią jednak doskonałe źródło do badań na śląską linią hrabiów Stolberg-Wernigerode z Dönhoffstädt.

Wśród zachowanych archiwaliów dużą wartość przedstawiają akta dotyczące stosunków osobistych, rodzinnych i majątkowych rodu. Na uwagę zasługuje zwłaszcza testament Udo Stolberga-Wernigerode, zawierający szczegółowy opis gospodarczy majątków należących do rodziny, ich dochodowość, a także udział kapitału w przedsiębiorstwach ${ }^{21}$. Cennych informacji dostarcza także jednostka o nazwie Erbhof Dönhoffstädt ${ }^{22}$, przedstawiająca szczegółowy stan posiadania właścicieli Dönhoffstädt. To korespondencja w sprawie przekształcenia dóbr dönhoffowskich z Fideikomissu w Erbhöfe, gromadzona przez ostatniego właściciela Dönhoffstädt - Albrechta. Zawiera ona wykaz majątków wschodniopruskich i śląskich z podaniem wielkości areału, informacje na temat parcelacji, a także funkcjonowania tartaków i cegielni, prowadzonych w dobrach Stolbergów, z opisem urządzeń technicznych i zdolności produkcyjnych ${ }^{23}$. Jej wartość wzbogacają ponadto wzmianki na temat genealogii rodów Dönhoff i Stolberg-Wernigerode.

Istotną, choć nieliczną grupę archiwaliów, stanowią akta administracyjno-gospodarcze. Są to głównie materiały odnoszące się do gospodarki leśnej, prowadzonej przez Stolbergów-Wernigerode w latach trzydziestych XX wieku. Na uwagę zasługują też, niezwiązane zupełnie z administracją lasów, akta dotyczące pałacu i zabudowań folwarcznych majątku Dönhoffstädt. Ciekawych informacji dostarcza zwłaszcza jednostka archiwalna Schloss Dönhoffstädt, opisująca nastroje panujące w Dönhoffstädt w ostatnich dniach II wojny światowej. Z pism w niej zawartych wynika, że głównym zmartwieniem

21 APO, Archiwum rodziny Dönhoff z Drogoszy pow. kętrzyński, sygn. 380/19.

22 Tamże, sygn. 380/21.

23 Wstęp do inwentarza zbioru akt podworskich rodziny Dönhoff, oprac. R. Kozłowska, Archiwum Państwowe w Olsztynie, s. 14. 
Stolbergów była troska o zabytkowy pałac. Poruszane są też kwestie związane z przygotowaniami do wyjazdu do Berlina ${ }^{24}$.

Osobny dział stanowią akta dotyczące politycznej, publicystycznej i naukowej działalności ostatniego właściciela Dönhoffstädt - Albrechta Stolberga-Wernigerode. Do najbardziej interesujących należą tu trzy tomy korespondencji politycznej Albrechta z lat 1929, 1930, 1935, odnoszące się głównie do polityki Niemiec w stosunku do traktatu wersalskiego, układu w Locarno, planu Dawesa i Jounga, a także stosunku tego państwa do Polski, ZSRR, Gdańska, Litwy ${ }^{25}$. Ciekawych informacji dostarczają też archiwalia odnoszące się do naukowej działalności Albrechta Stolberg-Wernigerode. Wśród nich znalazła się korespondencja w sprawie wydania jego pracy, poświęconej polityce Bismarka, a także stanowiące źródło historyczne, pisane na maszynie kopie korespondencji takich mężów stanu jak Bismark, Wilhelm I, Napoleon III $^{26}$. Słabe odbicie w aktach znajduje natomiast jego działalność jako członka Reichstagu.

$\mathrm{Z}$ omawianych archiwaliów korzystała jedynie autorka inwentarza do zespołu, Reneta Kozłowska, historyk Jerzy Skibiński, który napisał pracę na temat starostw dziedzicznych Prus Książęcych XVII i XVIII wieku ${ }^{27}$, a także nieliczni badacze zainteresowani rodem Dönhoffów, między innymi Kamila Wróblewska, która pisała na temat Bogusława i Władysława Dönhoffów ${ }^{28}$. Jak dotąd żaden z nich nie zajął się natomiast dziejami rodu Stolberg-Wernigerode, którego losy są równie ciekawe i godne uwagi. Materiałów na ich temat, podobnie zresztą jak do dziejów innych wschodniopruskich rodów, jest niewiele i do tego pozostają w dużym rozproszeniu. Mimo to stanowią dobrą podstawę do dalszych badań.

24 Tamże.

25 Tamże, s. 19.

26 Tamże, s. 20.

27 J. Skibiński, Starostwa dziedziczne Prus Książęcych w XVII i XVIII wieku: studium z dziejów przeobrażeń społeczno-ustrojowych, Olsztyn 1972.

28 K. Wróblewska, Portrety Bogustawa Dönhoffa - autora dziennika podróży do Warszawy z 1780 roku, Komunikaty Mazursko-Warmińskie, nr 3, 1981, s. 339-348; K. Wróblewska, Uwagi do biografii Wtadystawa Doenhoffa, Komunikaty Mazursko-Warmińskie, nr 3-4, 1988, s. 289-295. 
Marta Adamska

The current state of research on family history of Stolberg-Wernigerode Dönhoffstädt and their archives in the State Archives in Olsztyn.

Su m m a ry

Stolbergowie-Wernigerode were an old aristocratic family, completely unknown in Polish historiography. The origins of the family, but also development of the individual lines, may be reconstructed based on the nineteenth and early twentieth-century German heraldic and genealogical publications, as well as individual biographies of members of the family. To a certain degree information collected from above resources may be completed by an album dedicated to the noble's residencies situated in the Kingdom of Prussia in the nineteenth century, and also by the book 'Stolbergowie 1210-2010. Achthundertjährigen zur Geschichte des Geschlechts' published in 2010. Nevertheless, these resources do not provide a complete image of family life and their activities. In particular - omitted by researchers to date - was the Silesian branch of Stolberg-Wernigerode, which inherited the family fortune of the Prussian line of Dönhoffstädt - Dönhoff. Its fate has been recorded in family archives of Dönhoff family, preserved in the State Archives in Olsztyn. These family archives are a rich resource starting point for the family history of Stolberg-Wernigerode Dönhoffstädt. Documents regarding the following matters are of especially great value: personal relationships, family, family property, economic and administrative documents on the management of the Stolberg-Wernigerode forests in the ' 30 s of the twentieth century. One must also mention here documents of various activities of the last owner of Dönhoffstädt - Albrecht: political, journalistic and scientific. Nevertheless, the family history of Stolberg-Wernigerode family remains unknown, and in the shadow of the House of Dönhoff. 